\title{
BUILDING A BRIDGE BETWEEN PHYSICAL THERAPISTS AND FITNESS PROFESSIONALS: THE DEVELOPMENT OF A BUSINESS PLAN FOR SAN LUIS SPORTS THERAPY CLINICS
}

\author{
A Project \\ presented to \\ the Faculty of California Polytechnic State University, \\ San Luis Obispo
}

In Partial Fulfillment of the Requirements for the Degree Master of Science in Kinesiology

by

Ashley August Fittz

March 2010 
(C) 2010

Ashley August Fittz

ALL RIGHTS RESERVED 
COMMITTEE MEMBERSHIP

TITLE:

BUILDING A BRIDGE BETWEEN PHYSICAL

THERAPISTS AND FITNESS PROFESSIONALS:

THE DEVELOPMENT OF A BUSINESS PLAN FOR

SAN LUIS SPORTS THERAPY CLINICS

AUTHOR: $\quad$ Ashley August Fittz

DATE SUBMITTED: $\quad$ March 2010

COMMITEE CHAIR: $\quad$ Camille O’Bryant, Associate Professor and

Department Chair, Kinesiology Department

COMMITTEE MEMBER: Jenny Olmstead, Fieldwork/Internship Coordinator, Kinesiology Department

COMMITEE MEMBER: Matthew Wild, Chief Executive Officer/Chief Financial

Officer, San Luis Sports Therapy \& Orthopedic

Rehabilitation 


\title{
ABSTRACT \\ BUILDING A BRIDGE BETWEEN PHYSICAL THERAPISTS AND FITNESS \\ PROFESSIONALS: THE DEVELOPMENT OF A BUSINESS PLAN FOR SAN LUIS \\ SPORTS THERAPY CLINICS
}

\author{
Ashley August Fittz
}

The purpose of this project was to create a business plan for a profitable, selfsustaining, program to build a bridge between physical therapists and fitness professionals.

The Quick Fit Program was a new service for the existing business San Luis Sports Therapy. The program was designed to be implemented within each of the company's physical therapy clinics in California using existing personnel and resources. The Quick Fit Program is one way in which physical therapy practices can diversify the services they offer to keep pace with the changing landscape of healthcare.

Clients in the Quick Fit Program would receive an assessment of basic health and fitness during their initial visit. After the assessments, a licensed physical therapist debriefs each client and offers recommendations or referral to a physician or gym program as appropriate. Staff in the Quick Fit Program would also schedule a follow-up appointment three to six months from the date of the initial visit to assess any changes or improvements in health and fitness measures since the initial visit.

Keywords: Select Wellness program, physical therapy, post rehab, functional 


\section{ACKNOWLEDGMENTS}

I would like to thank my parents Ashley and Colleen Fittz for all of their love and support as I worked to complete this project. I would also like to thank the members of my committee, without their support and guidance this project would not have been possible. 


\section{CHAPTER}

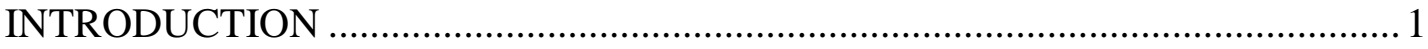

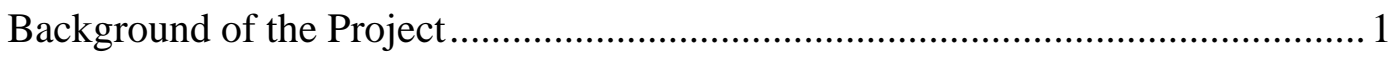

Statement of Purpose

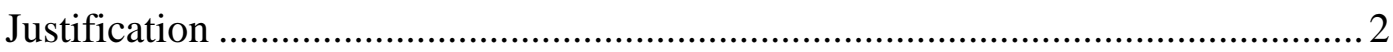

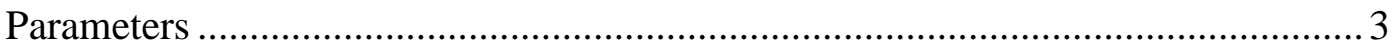

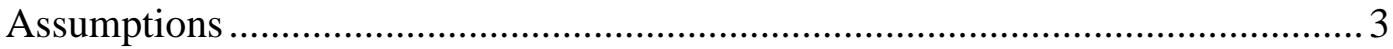

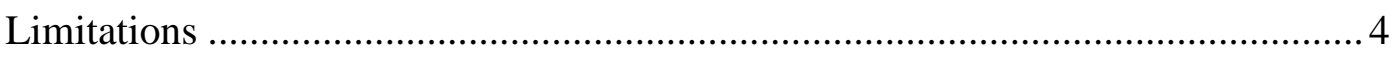

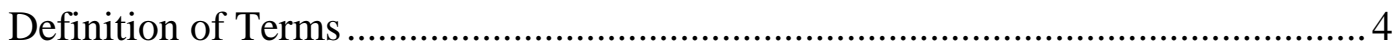

REVIEW OF LITERATURE ……………………….................................. 6

Statement of Purpose

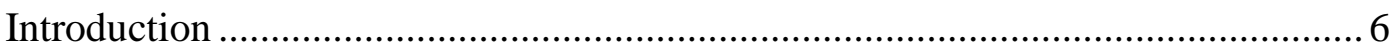

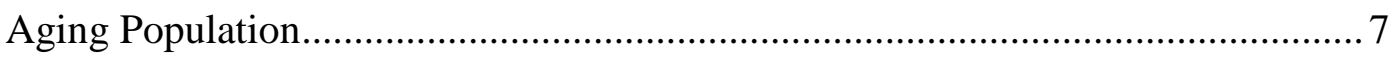

Increasing Popularity of Wellness Programs ........................................................

Barriers to Small Businesses Implementing Wellness Programs............................ 13

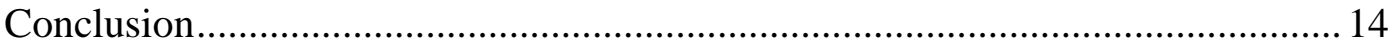

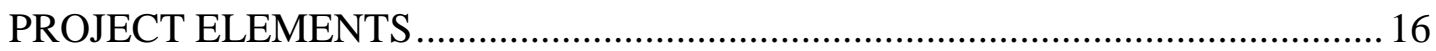

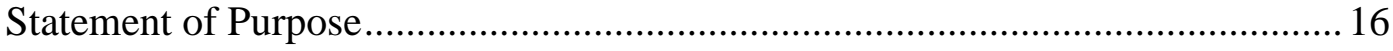

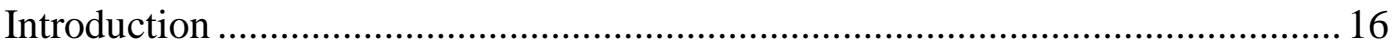

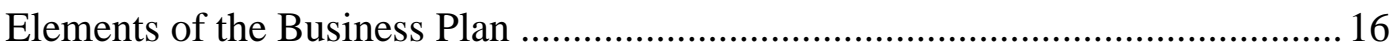

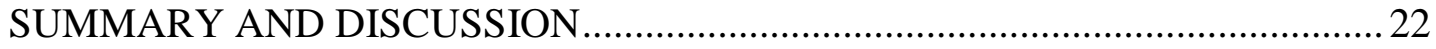




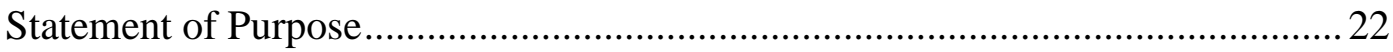

Summary and Discussion of Business Plan ................................................... 22

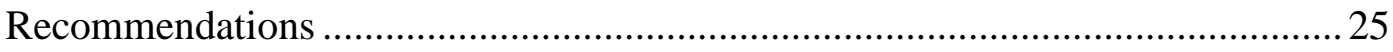

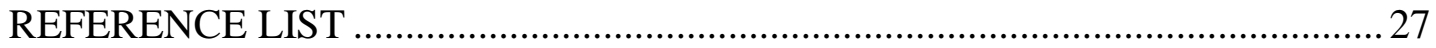

APPENDIX A: BUSINESS PLAN FOR QUICK FIT PROGRAM ........................ 31 


\section{Chapter 1}

Introduction

\section{Background of the Project}

Over the past twenty-plus years healthcare, in general, and physical therapy, in particular, have in many cases evolved into a subtle two-class system. The two-class system consists of people with poor health insurance coverage and people with good health insurance coverage. Many businesses cater to one class or the other. While many businesses may want to provide access to the widest-range of people as possible, they may jeopardize the high standards for quality of care that patients expect. Therefore, businesses will need to focus their efforts and strategies on ways to enhance the patient's experience and outcomes as efficiently as possible to be able to expand access while maintaining quality of care.

While striving to maintain high standards for quality of care, businesses must keep pace with other changes in the physical therapy industry. Physical therapy is a dynamic industry that is currently making a shift toward consumer driven healthcare, tightening reimbursement restrictions, and working to accommodate a growing Medicare population. The internet and other technology will play a larger and larger role in the evolution of the industry. Physical therapy, as an industry, will likely feel the impact of such changes as visits per patient decrease and the cost to deliver services increase.

Based on personal experience, as an attempt to control costs, providers in the physical therapy industry are likely to see some type of limitation on the number of visits from health insurance companies. Some health insurance companies may set restrictions 
on visits based on time frame or diagnosis while others may put caps on payments per time frame or diagnosis. More of these types of "risk-sharing" arrangements may directly or indirectly limit the number of visits and reimbursement amounts over the next few years.

Statement of Purpose

The purpose of this project was to create a business plan for a profitable, selfsustaining program to build a bridge between physical therapists and fitness professionals.

\section{Justification}

With increasing health insurance premiums, decreasing reimbursements, and an increasing demand for healthcare services from an aging population, healthcare providers need to find creative new ways to provide care. Individuals are becoming active consumers of healthcare services and more discerning of their healthcare providers.

Healthcare in the United States is undergoing a transformation as related spending continues to rise at the fastest rate in our history. According to the Kaiser Family Foundation and the Health Research and Educational Trust (Henry J. Kaiser Family Foundation, 2006, p. 1), "premiums for employer-sponsored health insurance in the United States have been rising four times faster on average than workers' earnings since 2000." Adding to the burden of rising costs, an aging population, increasing ethnic diversity, and a geographically shifting population will continue to transform the face of healthcare in the United States. As a result of this transformation, wellness programs 
have been gaining in popularity in an attempt to help contain the rising cost of healthcare. A study conducted by Pelletier (2001) found that "over 5 years, Blue Cross Blue Shield of Indiana realized a $250 \%$ return on its corporate fitness program investment, yielding a ROI (Return on Investment) of \$2.51 for every \$1.00 invested.”

\section{Parameters}

The project was delimited by the following parameters:

1. Thirteen physical therapy clinics in California.

2. Existing equipment and resources currently owned by the physical therapy clinics.

3. Existing personnel currently employed by each of the clinics, including physical therapists, physical therapy assistants and physical therapy aides.

\section{Assumptions}

The project was based on the following assumptions:

1. Over the next few years, increasingly higher interest rates will reduce the demand for money, thereby exacerbating inflationary pressures (Laffer, 2009). The resulting inflationary pressure will drive individuals to seek more value from money spent on their healthcare.

2. There will be a significant shift toward consumer driven healthcare. The two largest components will be Health Savings Accounts or HSA's (tax-free accounts that individuals spend on their healthcare needs) and uninsured (who may or may not qualify for federal/state assistance). 
3. The number of individuals on Medicare will grow as the population ages and people live longer.

4. The growing population of Medicare beneficiaries will have profound effects on healthcare.

5. Healthcare providers will come under continuing pressure to provide value at a lower cost or fewer visits.

\section{Limitations}

The Project was limited by the following parameters:

1. San Luis Sports Therapy clinic directors have a large degree of autonomy in the operation of their respective facility. Buy-in from clinic directors is necessary for the implementation of wellness programming at their facility.

2. While adding Obesity as an official diagnosis potentially bodes well for Physical Therapy, the move toward implementing wellness programs as reimbursed services is likely to occur slowly and may be further than five years out.

\section{Definition of Terms}

The following terms are defined as used in this project:

Health promotion. Health Promotion is the art and science of helping people discover the synergies between their core passions and optimal health, enhancing their motivation to strive for optimal health, and supporting them in changing their lifestyle to move toward a state of optimal health. Optimal health is a dynamic balance of physical, emotional, social, spiritual, and intellectual health. Lifestyle change can be facilitated 
through a combination of learning experiences that enhance awareness, increase motivation, and build skills and, most important, through the creation of opportunities that open access to environments that make positive health practices the easiest choice (O’Donnell, 2009, p. 3).

Healthcare provider. A provider of medical or health services and any other person or organization who furnishes, bills, or is paid for healthcare in the normal course of business (HIPAA.com, 2009)

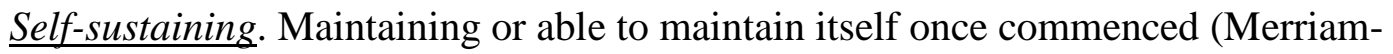
Webster's Online Dictionary, 2009).

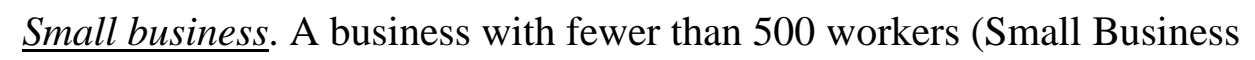
Administration, 2009). 


\section{Chapter 2}

Review of Literature

\section{Statement of Purpose}

The purpose of this project was to create a business plan for a profitable, selfsustaining program to build a bridge between physical therapists and fitness professionals.

\section{Introduction}

With the challenges faced by the physical therapy industry these recessionary times, healthcare providers in the industry are likely to see reduced visits and reimbursements. Therefore, it is important for clinics to expand their services and diversify to provide care to individuals. Existing physical therapy clinics need to prepare for a dynamic and challenging healthcare and physical therapy environment over the next several years. A profitable, self-sustaining and comprehensive wellness program could offer innovative responses to the anticipated challenges while maintaining an entrepreneurial approach to providing optimal healthcare in a physical therapy setting. This chapter contains information related to the rising cost of healthcare, aging of the population in the United States, increasing popularity of wellness programs, and the barriers encountered by small businesses in implementing wellness programs.

\section{Rising Cost of Healthcare}

One important difference between healthcare costs in the United States and those in other developed nations is the price per unit of care. Physician fees, payments 
per hospital day, and pharmaceutical prices are all higher in the United States than other developed nations (Organization for Economic Cooperation and Development, 2004). Although the United States does not provide a greater quantity of physician visits per capita than other nations, physician income is three times higher in the United States than in the average developed nation (Reinhardt, Hussey \& Anderson, 2002). Additionally, physicians in the United States receive higher fees for similar services than do physicians in other nations (Reinhardt et al., 1999; Fuchs \& Hahn, 1990).

Another important distinction of the healthcare system in the United States is the cost of pharmaceutical products. Many pharmaceutical products improve the quality of life and prevent the costly complications of disease and illness. However, the costs of these products have been increasing at a fast pace. According to Levit et al. (2005), "Costs increased more than 15\% each year from 1998 to 2002." Danzon and Furukawa (2003) compared similar medications in the United States to those in Canada, France, Germany, and the United Kingdom. They found that Canadian and French prices are about $60 \%$ of those in the United States. Germany and the United Kingdom are about $85 \%$ of those in the United States. They also found that differences were wider for brand-name than for generic pharmaceutical products.

As the cost of healthcare rises, healthcare providers are also facing a growing aging population in need of their services.

\section{Aging Population}

The HRSA (Health Resources and Services Administration) of the United States Department of HHS (Health and Human Services) identifies the following demographic trend: 
The population is aging and the size of the elderly population will increase substantially. An aging population will place greater demands on the health system at the same time that many health professionals will be retiring. In the United States, the proportion of the population 65 years or older is projected to increase from $12.4 \%$ in 2000 to $19.6 \%$ in 2030 (U.S. Census Bureau).

The proportion of working adults in the United States 65 years of age or older is projected to increase and surpass that of the large post-World War II baby boomers by 2010 (Manton, et al., 2007). As a result of the aging work force, the average health and functional capacity of individuals 65 years of age or older must improve sufficiently for them to be physically and cognitively capable of continuing to work. In order for this to happen, there will need to be greater investments in research, public health, and healthcare.

In a report from the National Census Bureau, Kinsella and Wan (2008) stated, "Population aging has and will have large effects on social entitlement programs, labor supply, and total savings around the globe" (p. 1). Chronic diseases, which affect older adults disproportionately, diminish quality of life and increase healthcare costs. Social entitlement programs like Medicare and Medicaid will experience an increased demand in services. If healthcare is not reformed and structured to accommodate the forecasted increase in the aging population now, the aging population will force a change in healthcare later.

The increasing proportion of adults in the United States 65 years or older may result in greater rationing of healthcare services and has the potential to impact quality of care. According to Hellmich (2008): 
Half of all trips to doctors' offices were made by people with chronic medical conditions. High blood pressure was the most common ailment, followed by arthritis, high cholesterol, diabetes and depression. (II12)

Much of the stress placed on the healthcare system can be alleviated through greater emphasis on wellness programming which emphasizes prevention and management of chronic ailments through behavior change, nutrition, and exercise. The increasing popularity of wellness programs is due to their effectiveness at reducing healthcare costs, thereby reducing stress on the healthcare system.

\section{Increasing Popularity of Wellness Programs}

The increasing popularity of wellness programs is due to their economic success and improved measures of health experienced by participants. Aldana and Pronk (2001) conducted a review of literature and found that health promotion programs can lead to a reduction in healthcare costs and reduced absenteeism by up to $20 \%$

Aldana (2001) reviewed 72 studies to summarize the literature on health promotion programs and their impact on employee-related healthcare expenditures and absenteeism. Both the nature of the findings and the overall quality of the literature were evaluated in an attempt to answer two questions: Do individuals or populations with high health risks have worse financial outcomes than individuals or populations with low health risks? Aldana (2001) found that health promotion programs were associated with lower levels of absenteeism and healthcare costs, while fitness programs are associated with reduced healthcare costs. 
Fries et al. (1993) performed a study of 4,712 Bank of America retirees to evaluate the effectiveness of a health promotion program in terms of health risk reduction and reduction in medical costs. The participants of the study were randomly divided into three groups and followed for 24 months. Group 1, the intervention group, received a low-cost, individualized health promotion program including risk appraisal, recommendation letters, and self-management materials. All materials were delivered entirely through the mail. Group 2 received risk appraisals only, without feedback, for the first 12 months. The full intervention for Group 2 was given during the last 12 months of the 24 month study. Group 3 was followed using claims data only. The overall health risk scores for all participants in the study improved by $12 \%$ over that experienced by the control group. During the first 12 months of the randomized control period of the study, cost reductions averaged $\$ 164$ in the intervention group. This contrasted with an average increase of $\$ 15$ in the control groups. The authors of the study concluded that risk reduction programs directed at retiree populations can improve health risk status and reduce costs.

Fries and McShane (1998) undertook a study to identify individuals with a high use of medical services and target them for health promotion and selfmanagement intervention. Fries and McShane (1998) compared health risk in 2,586 high-risk persons with those of other groups and contrasted results in specific disease or behavior categories. The researchers used interventions that were a standard generic health education program and a similar program directed at high risk individuals. Health risk scores were found to have improved by $11 \%$ overall. Total costs were reduced by $\$ 484$ in the high-risk group and the return on investment was about 6:1. As a result of their findings, Fries and McShane (1998) concluded that 
"effective health education programs can result in larger changes in use and costs in high-risk persons than in unscreened persons, justifying more intensive educational interventions in high-risk groups."

Goetzel et al. (1998) performed a study which focused on alternative methods for evaluating the impact of Chevron Corporation's Health Quest Fitness Center program. The researchers looked at the program's impact on medical expenditures. They compared inpatient and pharmacy costs for program participants and nonparticipants over a two and a half year period. Results of the study showed that compared with non-participants, costs for participants were significantly lower for participants who used a Health Quest fitness center at least twice weekly.

Goetzel et al. (1998) performed an additional study which was published in the Journal of Occupational and Environmental Medicine. In this study, the researchers looked at lifestyle-related medical care costs for employees of a major corporation who were participating in a worksite health promotion program. They collected their data over a three-year period and compared the costs for nonparticipants in a cross-sectional study. The population used in the study consisted of 8,334 active employees of the Procter \& Gamble Company. Participants of the worksite health promotion program had significantly lower healthcare costs when compared with non-participants in the third year of the program. In the third year of the program, participants had significantly lower inpatient costs, fewer hospital admissions, and fewer hospital days of care when compared with non-participants. The researchers found no significant differences in costs between participants and non-participants during the first two years of the worksite health promotion program. Goetzel et al. (1998) concluded, "Long-term participation in a worksite health 
promotion program that includes high-risk screening and intensive one-on-one counseling results in lower total and lifestyle-related healthcare costs, as well as lower utilization of hospital services."

Ozminkowski et al. (1999) studied a comprehensive health and disease management program at Citibank. The program at Citibank included an initial screening of employees, extensive follow-up with the higher risk subjects, and general health education and awareness building. The objective of the study was to estimate the financial impact of Citibank's program on medical expenditures. The study consisted of 22,838 participants, with 11,194 program participants and 11,644 nonparticipants. Program participants were followed for an average of 38 months before and after administration of a health risk appraisal (HRA). Dollar savings that resulted from the program were compared to program costs to estimate the economic return on the company's investment in the program. According to Ozminkowski et al. (1999), "The return on investment (ROI) was estimated to be between $\$ 4.56$ and $\$ 4.73$ saved per dollar spent on the program, depending on the discount rate applied" (p. 39). The strong, positive ROI shown in this study suggests that a health management program, which focuses interventions on high risk populations, can result in financial savings to an organization.

Serxner et al. (2003) performed a study to determine whether participation in the health risk assessment component of a comprehensive health promotion program has an impact on medical costs. 13,048 program participants were compared with 13,363 non-participants to determine the programs impact on medical costs. Overall, participants of the health risk assessment cost an average of \$212 less than nonparticipants. As participation in the health risk assessment increased, cost savings also 
increased. The researchers found that participation in either a health risk assessment or activities alone resulted in savings, participation in both resulted in even greater benefits. Their findings support the notion that there is an independent benefit of each of these components of participation, and that the sum of the components provides a greater benefit than the impact of either of the individual components alone.

\section{Barriers to Small Businesses Implementing Wellness Programs}

Small businesses, defined as those with fewer than 500 workers, make up about $99 \%$ of employers in the United States and employ more than half of the private sector workforce. (Small Business Administration, 2009). Despite the enormous potential for wellness programs to improve the health of employees in the United States, most of the reports of wellness programs in peer reviewed literature occur in larger businesses.

Regardless of the need for wellness programs and their increasing popularity, such programs are not widely embraced by small businesses. Small businesses typically have a lack of dedicated resources, lower profit margins, and limited access to commercial worksite vendors, all of which pose significant challenges to implementing wellness programs.

Among the barriers facing small businesses in implementing wellness programs is a lack of dedicated resources. Many small businesses have a limited human resources staff. Therefore, they are unlikely to have experts who know how to design and organize a wellness program or who can commit the time to develop those skills (McMahan et al., 2001). According to Linnan et al. (2008), this is problematic because worksites with a staff person assigned to health promotion are 10 times more 
likely than a worksite without a dedicated resource to have a comprehensive wellness program, regardless of worksite size.

Secondly, small businesses tend to have lower profit margins than larger businesses, making it difficult to invest in and sustain wellness programs (Stokols et al., 2001). Additionally, according to McMahan et al (2001) small businesses are often overwhelmed with health and safety regulations, making them unlikely to establish wellness programs not mandated by law.

Thirdly, small businesses also tend to have limited access to commercial worksite vendors. Although some health insurance providers offer some forms of wellness programs, these are often limited and are only provided through the healthcare system. To further add to this barrier, many small businesses do not offer health insurance benefits to employees (McMahan et al., 2001).

A lack of dedicated resources, lower profit margins, and limited access to commercial worksite vendors, are all significant challenges to an entrepreneur implementing a wellness program within a small business.

\section{Conclusion}

As more and more individuals feel the financial impact of their healthcare decisions, they are more likely to be more demanding of and less willing to purchase those services. This could result in significant reductions in the utilization of physical therapy services as they are currently offered.

As an attempt to control costs, healthcare providers are likely to see from all payers, an evolution of some type of limitation on visits. This may be in the form of 
explicit limits or limits forced through reimbursement constraints. Some may have restriction of visits based on time frame or diagnosis while others will put caps on payments per time frame or diagnosis.

With the challenges the physical therapy industry will face with reduced visits and reimbursements, it is important for clinics to expand their services and diversify to provide care to individuals. Existing physical therapy clinics need to prepare for a dynamic and challenging healthcare and physical therapy environment over the next several years. A profitable, self-sustaining, program to build a bridge between physical therapists and fitness professionals should offer innovative responses to the anticipated challenges while maintaining an entrepreneurial approach. Therefore, I developed a business plan for the Quick Fit Program (QFP) with these issues in mind. 


\section{Chapter 3}

\section{Project Elements}

\section{Statement of Purpose}

The purpose of this project was to create a business plan for a profitable, selfsustaining program to build a bridge between physical therapists and fitness professionals.

\section{Introduction}

San Luis Sports Therapy is a locally owned physical therapy business with 13 clinics in California and two in Arizona. Clinics are beginning to incorporate wellness programs into their practice. The wellness programs can attract both non-patients to the clinic as well as transition existing patients into ongoing clients. This will be a necessity for physical therapists in the competitive consumer driven market of the future. This business plan for a comprehensive wellness program primary focus is on clinics on the Central Coast of California.

The objectives of the proposed wellness program are to provide:

1. Preventative physical health services

2. Educational and informational health services

3. Post-therapy/post-procedure wellness services

4. Wellness services that improve current quality of life

\section{Elements of the Business Plan}


The elements of the business plan for this project were chosen after consulting the U.S. Small Business Administration (SBA) website. The SBA is an independent federal government agency to aid, counsel, assist, and protect small business in the United States. According to the SBA (Small Business Administration, 2009), the essentials of a good business plan are an Executive Summary, Market Analysis, Company Description, Organization \& Management, Marketing \& Sales Management, Service or Product Line, Funding Request, Financials, and Appendix.

Based on this information, I chose to include the following elements in my business plan: Executive Summary, Company Summary, Services, Market Analysis Summary, S.W.O.T. Analysis, Management Summary, and Financial Plan.

Executive Summary. The state of America's healthcare, coupled with an aging population and the rising cost of providing healthcare pose a threat to businesses. At the same time, decreasing reimbursements and limits on the number of visits threaten physical therapy practices unless they diversify and expand their services. Small businesses struggle with managing costs while providing value to employees. In contrast, large businesses are able to offset healthcare costs and provide value to employees by implementing wellness programs. While physical therapy practices need to find other sources of revenue, small businesses risk being left behind as other businesses are able to reduce healthcare costs, and provide value to retain and recruit employees.

Small businesses, defined as those with fewer than 500 workers, make up about $99 \%$ of employers in the United States and employ more than half of the private sector workforce (Small Business Administration, 2009). Despite the enormous 
potential for wellness programs to improve the health of employees in the United States, such programs are not widely embraced by small businesses. Small businesses typically have a lack of dedicated resources, lower profit margins, and limited access to commercial worksite vendors, all of which pose significant challenges to implementing wellness programs.

Challenges faced by small businesses and changes in the physical therapy industry create a huge need that is not currently being met. This is the perfect opportunity for the Quick Fit Program (QFP). The program increases revenue for physical therapy practices and serves as a gateway to wellness programs for small businesses. The Quick Fit Program (QFP) also gives small businesses a cost-effective method to provide value to employees while offsetting healthcare costs.

The Quick Fit Program (QFP) is much like a six month or annual check-up with a dentist. Clients in the program will receive health and fitness assessments, recommendations from a physical therapist, and referral to another fitness or medical professional as appropriate. The program provides assessments every three to six months and serves as a gateway to other wellness programs through the following actions:

1. Encouraging clients to take action to improve their health and fitness.

2. Providing a referral to an appropriate wellness program.

3. Measuring progress through health and fitness assessments.

The Quick Fit Program (QFP) will serve small businesses in California, helping employees of small businesses to become healthier, while lowering overall healthcare costs through health and fitness assessments, referral to appropriate health 
professionals, and access to a team of rehabilitation and fitness experts. Providing health and fitness assessments along with recommendations are a natural extension of physical therapy, and positions physical therapists as a valuable community resource while providing new revenue for physical therapy practices.

Company Summary. The Quick Fit Program (QFP) is based on the belief that in order to keep up with the changing healthcare landscape, physical therapists need to diversify their services and offer on-going health and fitness assessments and programs to the communities they serve. For this reason, the Quick Fit Program (QFP) combines health and fitness assessments and serves as a gateway to wellness programs to facilitate positive lifestyle changes in members of the community.

Services. The Quick Fit Program (QFP) is much like the six month or annual check-up with a dentist. Clients in the program will receive health and fitness assessments, recommendations from a physical therapist, and referral to another fitness or medical professional as appropriate.

Market Analysis Summary. The amount of reimbursement received for physical therapy services has remained largely flat over the past several years. In the same amount of time, the amount of required documentation has exponentially increased in volume as well as in complexity. The increase in documentation requirements with a relatively flat level of reimbursement does not keep pace with inflation. This effectively lowers the cost of reimbursement even further. These factors combine to produce lower levels of professional productivity due to extensive documentation time, and increased cost for additional office staff to support claims processing. The end result is working harder for less profit. 
The target market for the Quick Fit Program (QFP) are small businesses, but other potential users of the program consist of discharged physical therapy patients, local athletic teams, and other adult members of the local community.

S.W.O.T. Analysis Advantages and challenges are present considering the organizational structure of San Luis Sports Therapy. With centralized administrative and billing teams, we are able to streamline processes and cut costs per location by servicing multiple locations. This fact, in addition to the size of our company, allows for more specialization than competitors which positions us better than most for the upcoming challenges during these turbulent economic times.

Management Summary. The Quick Fit Program (QFP) is a turnkey program that will be managed by the director of the participating physical therapy clinic. The San Luis Sports Therapy team will provide operational support to participating clinics. Operational support will include the following:

1. Design of marketing material is not limited to, but will include brochures, client handouts, posters, and web site design and maintenance.

2. Periodic questionnaires sent to clients to solicit feedback.

3. Tracking of program metrics.

4. Training/certification of staff.

All work in implementing the program at the clinics will be performed by existing staff at the physical therapy clinic. A physical therapy aide will perform the assessments during the first 15 minutes with the client. After the assessment, the client will meet with a physical therapist to review assessment results and answer any 
questions. The physical therapist will conclude by creating an action plan and schedule a follow up assessment. The action plan will consist of strategies and an exercise plan for the client to improve their score on the follow up assessment.

Assessments will be scheduled during normal business hours and will not require additional payroll expense.

Financial Plan. The business plan contains a basic financial projection for the first five years of operation. To minimize expense, the program makes use of existing resources and personnel. Refer to the Business Plan in Appendix A for the complete financial plan. 


\section{Chapter 4}

\section{Summary and Discussion}

\section{Statement of Purpose}

The purpose of this project was to create a business plan for a profitable, selfsustaining program to build a bridge between physical therapists and fitness professionals.

\section{Summary and Discussion of Business Plan}

The business plan for the Quick Fit Program(QFP) is based on the belief that in order to survive and keep up with the changing healthcare landscape, physical therapists need to expand their services and offer on-going health and fitness assessments and programming to the communities they serve.

The program will be implemented as an additional service provided by San Luis Sports Therapy using existing personnel and resources. Using existing resources, the program will initially rely upon referrals from physical therapists and local contacts in the community to build a client base. As the program develops a client base and demonstrates increased revenue for participating clinics, additional marketing and promotional outlets will be explored.

The keys to success for the program are its utilization of existing company resources and thirty minute timeframe for health and fitness assessments and client debriefing. The program has the potential to add very little expense to the operation of the participating clinic and keeps the program within an acceptable timeframe for both staff and clients. 
Market segments based on potential users of the Quick Fit Program (QFP) are discharged physical therapy patients, local businesses looking for wellness programming, and adult members of the local community searching to make lifestyle choices that are preventative in nature.

All work in the program will be performed by existing staff at the physical therapy clinic. A physical therapy aide will perform assessments during the first fifteen minutes with the client. After the assessment the client with meet with a physical therapist to review assessment results, answer questions, and discuss recommendations for improvement and follow-up.

\section{Preparation for Implementation}

The key to making the Quick Fit Program a success was to first get buy-in from clinic directors and staff. Without their support the program would have been doomed to fail. The process of getting buy-in was done over the course of several months by first communicating the need and urgency for such a program. The company's internal website along with email and personal meetings was used to convey the need and urgency for the new program. A case was made that during these recessionary times and with the declining reimbursements from insurance companies, many physical therapy practices will go out of business unless they find new ways to generate revenue and increase referrals. As a whole, business practices in the physical therapy industry are poor and physical therapists tend to resist change and collaboration with other health professionals. As a result, the process of getting buy in from clinic directors who are all physical therapists was long and slow. Success in getting buy-in came when their fear of declining revenue was given focus. By illustrating how the clinic directors will be seeing drastic reductions in 
reimbursements and referrals over the next several years, they were willing to try the Quick Fit Program (QFP) to help address their fears.

\section{Pilot Testing}

Once buy-in from several clinic directors was achieved, the next step was pilot testing then implementation. Prior to implementation the Quick Fit Program (QFP) was first pilot tested in the San Luis Sports Therapy clinic located in Orcutt. The objective of the pilot testing was to refine forms, procedures, and training associated with the program.

One of the findings from the pilot test indicated that staff needed more training in how to conduct the health and fitness assessments and convey a high degree of value to the client. Basically, sales training or training similar to that of a Personal Trainer was needed. The solution was to hold a training or certification workshop for the Quick Fit Program (QFP) prior to implementing it in the other clinics. The workshop conducted was four hours in length and involved a lot of hands of practice and training in how to conduct the assessments in the program.

A second finding from the pilot test revealed the need for improved client handouts. The initial handouts were not aesthetically pleasing and contained too much information. The solution was to condense the information on each handout and to add color pictures and graphs.

Thirdly, the need for better data sheets and spreadsheets to perform calculations was made apparent through the pilot test. The solution incorporated 
feedback from staff involved in the pilot test and resulted in easier to use data sheets and more functional and valuable spreadsheets.

\section{Implementation}

After pilot testing the program for approximately three months it was implemented in San Luis Sports Therapy clinics in San Luis Obispo, Atascadero, Morro Bay, and Templeton. The program was not implemented in Santa Maria, Arroyo Grande, and Paso Robles due to other limitations. These limitations included available space, equipment, and willingness of the clinic director to add an additional program to the services they offer.

\section{Recommendations}

As a result of pilot testing then implementing the program, several recommendations became apparent. The recommendations relate to communicating value to clients and developing and maintaining relationships with clients and other businesses in the community.

Whatever value the company or staff assigns to the program, the client establishes their own sense of value for the program based on their experience. If clients do not perceive a high degree of value they are unlikely to become repeat consumers or recommend the program to a friend or family member. Therefore, the first recommendation is for future programs to develop systems or methods to specifically address this need to convey a high degree of value to the client.

Currently, physical therapists may develop relationships with local physicians or surgeons, but seldom with other members of the local business community. As a 
result, they are missing out on the benefits of a referral network with other business such as fitness centers, retail stores, and alternative health practitioners. It's therefore recommended that future programs create tools or specific training to make it easier for physical therapists to develop and maintain relationships within their local business community.

Lastly, another recommendation for future programs is to find a way to make clients repeat consumers. As found with the Quick Fit Program (QFP), clients will try the service once because it's novel or interesting. However, getting clients to repeatedly utilize the service over time became difficult. Future programs would benefit from creating systems or methods to keep clients motivated and interested in utilizing the service repeatedly over time. 


\section{Reference List}

Aldana, S.G. (2001). Financial impact of health promotion programs: A comprehensive review of the literature. American Journal of Health Promotion, 15(5), 296-320.

Aldana, S.G. \& Pronk, N.P. (2001). Health promotion programs, modifiable health risks and employee absenteeism. Journal of Occupational and Environmental Medicine, 43, 36-46.

Danzon, P.M. \& Furukawa M.F. (2003). Prices and availability of pharmaceuticals: evidence from nine countries. Retrieved October 29, 2003, from http://content.healthaffairs.org/cgi/content/full/hlthaff.w3.521v1/DC1

Fries, J. F., Bloch, D., Harrington, H., Richardson, N., \& Beck, R. (1993). Two-year results of a randomized controlled trial of a health promotion program in a retiree population: The Bank of America study, American Journal of Medicine, 94, 455-462.

Fries, J. F. \& McShane, D., (1998). Reducing need and demand for medical services in high-risk persons, Western Journal of Medicine, 169(4), 201-207.

Fuchs VR, Hahn JS. (1990). A comparison of expenditures for physicians' services in the United States and Canada. New England Journal of Medicine, 323, 884-890.

Goetzel, R. Z., Dunn, R. L., Ozminkowski, R.J., Satin, K., Whitehead, D., \& Cahill, K. (1998). Differences between descriptive and multivariate estimates of the impact of Chevron Corporation's health quest program on medical expenditures, Journal of Occupational and Environmental Medicine, 40(6), 538-545. 
Goetzel, R. Z., Jacobson, B. H., Aldana, S. G., Vardell, K., \& Yee, L. (1998). Health care costs of worksite health promotion participants and non-participants, Journal of Occupational and Environmental Medicine, 40(4), 341-346.

Hellmich, N. (2008). Aging population making more visits to the doctor's. Retrieved August 7, 2008, from http://www.usatoday.com/news/health/2008-08-06er_N.htm

Henry J. Kaiser Family Foundation. (2006, September 26). Employee Health Benefits: 2006 Annual Survey.

HIPAA.com. (2009). The definition of healthcare provider. Retrieved December 19, 2009, from http://www.hipaa.com/2009/05/the-definition-of-health-careprovider/

Kinsella, K., Wan, H. (2008). An aging world: 2008 international population reports. U.S. Census Bureau, June 2009, p. 1.

Laffer, A. (2009). Get ready for inflation and higher interest rates. Retrieved January 2, 2010 from http://online.wsj.com/article/SB124458888993599879.html

Levit, K, Smith, C, Cowan, C, Sensenig, A, \& Catlin, A. (2004). Health spending rebound continues in 2002. Health Affairs, 23(1): 147-159.

Linnan, L., Bowling M., Childress, J., Lindsay G., Blakey, C., Pronk, S. et al. (2008). Results of the 2004 National Worksite Health Promotion Survey, American Journal of Public Health, 98(8), 1503-1509.

Linnan, L.A. \& Birken, B.E. (2006). Small businesses, worksite wellness, and public health: a time for action, North Carolina Medical Journal, 67(6), 433-437. 
Manton, K.G., Lowrimore, G.R., Ullian, A.D., Gu, X.L. \& Tolley, D.H. (2007, June 26) Proceedings of the National Academy of Sciences of the United States 104.26, 10802-10806.

McMahan S., Wells, M., Stokols, D., Philips, K., Clitheroe, H.C. (2001). Assessing health promotion programming in small businesses, American Journal of Health Studies, 17(3), 120-128.

Merriam-Webster's Online Dictionary. (2009). Self-sustaining. Retrieved December 19, 2009, from http://www.merriam-webster.com/dictionary/self-sustaining

O'Donnell, M. (2009). Definition of health promotion 2.0: embracing passion, enhancing motivation, recognizing dynamic balance, and creating opportunities, American Journal of Health Promotion, 23(6), 3.

Organization for Economic Cooperation and Development. (2004). A Disease-based Comparison of Health Systems. Retrieved December 7, 2004, from http://www.oecd.org

Ozminkowski, R.J., Dunn, R., Goetzel, R., Cantor, R., Murnane, J., \& Harrison, M. (1999). A return on investment evaluation of the Citibank, N.A. health management program, American Journal of Health Promotion, 14(1), 31-43.

Pelletier, K.R. (2001). A Review and Analysis of the Clinical- and Cost-Effectiveness Studies of Comprehensive Health Promotion and Disease Management Programs at the Worksite: 1998-2000. American Journal of Health Promotion, 4(2) 128-133. 
Reinhardt, U.E., Hussey P.S., \& Anderson G.F. (1999). Cross-national comparisons of health systems using OECD data, Health Affairs, 21(3), 169-181.

Serxner, S. A., Gold, D. B., Grossmeier, J. J., \& Anderson, D. R., (2003). The relationship between health promotion program participation and medical costs: A dose response. Journal of Occupational and Environmental Medicine, 54(11), 1196-1200.

Small Business Administration. (2009). Advocacy: The Voice of Small Business in Government. Retrieved February 13, 2010, from http://www.sba.gov/advo/stats/sbfaq.pdf

Small Business Administration. (2009). Write a Business Plan. Retrieved December 20, 2009, from http://www.sba.gov/smallbusinessplanner/plan/writeabusinessplan/SERV_ESSE NTIAL.html

Stokols, D., McMahan, S., \& Phillips, K., (2001). Health promotion in the workplace. $3^{\text {rd }}$ edition. Albany, NY: Delmar Publishers, Inc.

U.S. Department of Health and Human Services. (2004). Changing Demographics: and the Implications for Physicians, Nurses, and Other Health Workers. Retrieved April 7, 2004, from http:// bhpr.hrsa.gov/healthworkforce 
Appendix A: Business Plan for Quick Fit Program 
BUSINESS PLAN FOR THE QUICK FIT PROGRAM (QFP):

BUILDING A BRIDGE BETWEEN PHYSICAL THERAPISTS AND FITNESS

PROFESSIONALS

\author{
San Luis Sports Therapy \\ 805 Aerovista Pl., Suite 201 \\ San Luis Obispo, CA 93401
}

by

Ashley August Fittz

March 2010 
(C) 2010

Ashley August Fittz

ALL RIGHTS RESERVED 
SECTION

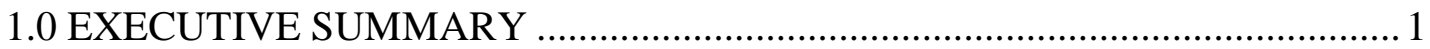

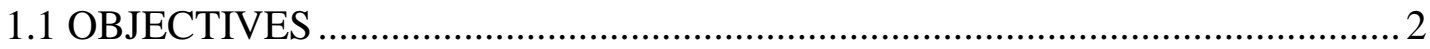

1.2 MISSION

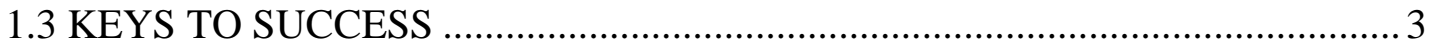

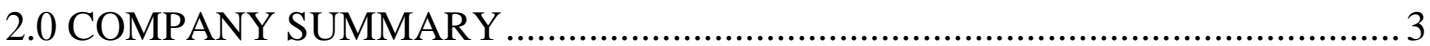

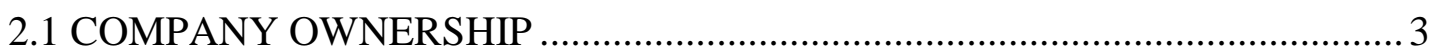

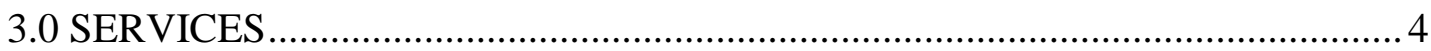

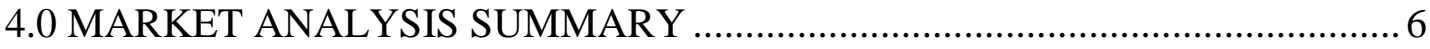

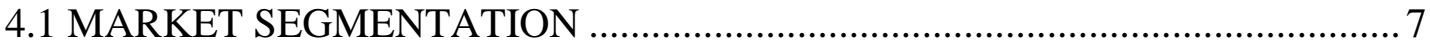

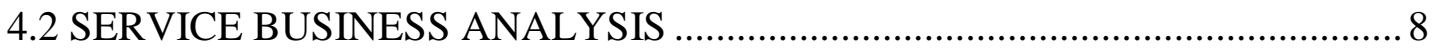

5.0 STRATEGY AND IMPLEMENTATION SUMMARY ..................................

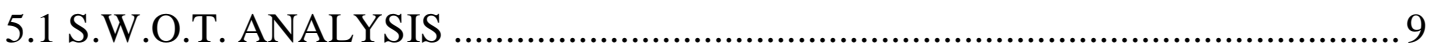

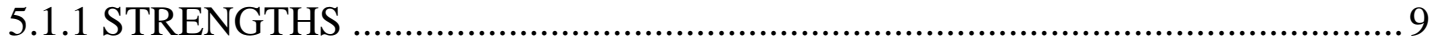

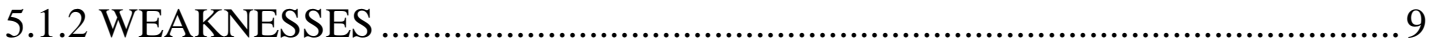

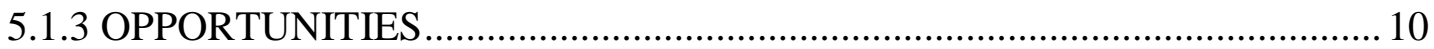

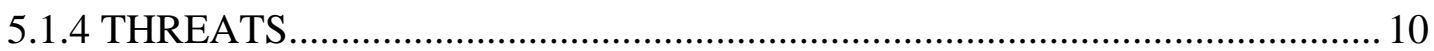

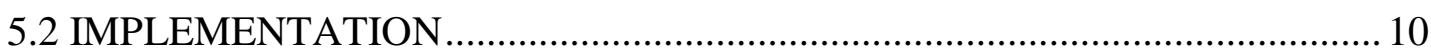

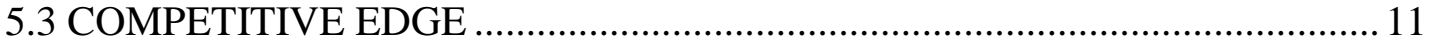

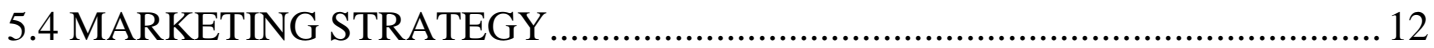

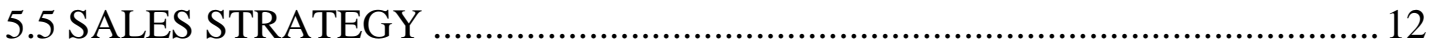

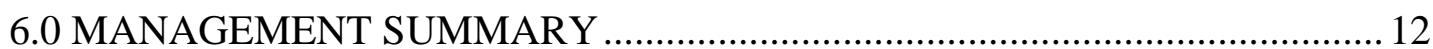

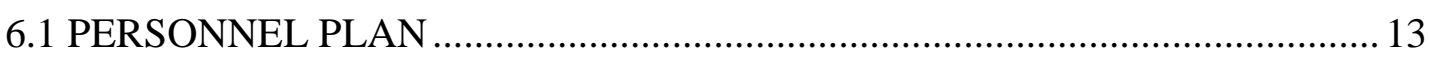


7.0 FINANCIAL PLAN......

13 


\subsection{Executive Summary}

The state of America's healthcare, coupled with an aging population and the rising cost of providing healthcare pose a threat to businesses. At the same time, decreasing reimbursements and limits on the number of visits threaten physical therapy practices unless they diversify and expand their services. Small businesses struggle with managing costs while providing value to employees. In contrast, large businesses are able to offset healthcare costs and provide value to employees by implementing wellness programs. While physical therapy practices need to find other sources of revenue, small businesses risk being left behind as other businesses are able to reduce healthcare costs, and provide value to retain and recruit employees.

Small businesses, defined as those with fewer than 500 workers, make up about $99 \%$ of employers in the United States and employ more than half of the private sector workforce. (Small Business Administration, 2009). Despite the enormous potential for wellness programs to improve the health of employees in the United States, such programs are not widely embraced by small businesses. Small businesses typically have a lack of dedicated resources, lower profit margins, and limited access to commercial worksite vendors, all of which pose significant challenges to implementing wellness programs.

Challenges faced by small businesses and changes in the physical therapy industry create a huge need that is not currently being met. This is the perfect opportunity for the Quick Fit Program (QFP). The program increases revenue for physical therapy practices and serves as a gateway to wellness programs for small businesses. The Quick Fit Program (QFP) also gives small businesses a cost-effective method to provide value to employees while offsetting healthcare costs.

The Quick Fit Program (QFP) is much like a six month or annual check-up with a dentist. Clients in the program will receive health and fitness assessments, recommendations from a 
physical therapist, and referral to another fitness or medical professional as appropriate. The program provides assessments every three to six months and serves as a gateway to other wellness programs through the following actions:

4. Encouraging clients to take action to improve their health and fitness.

5. Providing a referral to an appropriate wellness program.

6. Measuring progress through health and fitness assessments.

The Quick Fit Program (QFP) will serve small businesses in California, helping employees of small businesses to become healthier, while lowering overall healthcare costs through health and fitness assessments, referral to appropriate health professionals, and access to a team of rehabilitation and fitness experts. Providing health and fitness assessments along with recommendations are a natural extension of physical therapy, and positions physical therapists as a valuable community resource while providing new revenue for physical therapy practices.

\subsection{Objectives}

1. To provide a wellness program solution to small businesses, by offering an effective, affordable, turn-key program that will generate additional revenue for physical therapy clinics.

2. To position physical therapists as a valuable health and fitness resource in their community.

3. To develop partnerships between physical therapists and fitness professionals.

4. To serve at a gateway to wellness programs. 


\subsection{Mission}

The Quick Fit Program (QFP) is a fitness assessment service that helps small businesses provide one of the greatest gifts of all to employees, that of good health. Personal gains such as improved self-esteem and self-motivation, combined with measurable benefits will create tremendous advantages for clients.

\subsection{Keys to Success}

The programs' keys to success are:

1. Utilization of existing San Luis Sports Therapy resources such as trained staff and business ties in the community.

2. Marketing the program to small businesses.

3. Maintaining a low overall cost of program implementation and management by use of simple and effective systems.

\subsection{Company Summary}

The Quick Fit Program (QFP) is based on the belief that in order to keep up with the changing healthcare landscape, physical therapists need to diversify their services and offer ongoing health and fitness assessments and programs to the communities they serve. For this reason, the Quick Fit Program (QFP) combines health and fitness assessments and serves as a gateway to wellness programs to facilitate positive lifestyle changes in members of the community.

\subsection{Company Ownership}


The Quick Fit Program (QFP) is a new service offered by San Luis Sports Therapy and its affiliates.

\subsection{Services}

The Quick Fit Program (QFP) will serve small businesses in California by providing the following assessments:

- Blood pressure

- Resting heart rate

- Oxygen saturation

- Height

- Weight

- Waist circumference

- Body composition

- Balance

- Grip strength

- Functional movement assessment

- Cardiovascular risk stratification

- Assessment of possible areas for future concern

- Recommendations on improving health and fitness measures

- Referral to physician, physical therapy, or other fitness professionals in the community if appropriate

- Referral to a wellness program as appropriate

The Quick Fit Program (QFP) is much like the six month or annual check-up with a dentist. Clients in the program will receive health and fitness assessments, recommendations from a physical therapist, referral to another fitness or medical professional, and referral to a wellness 
program as appropriate. The program provides assessments every three to six months and serves as a gateway to other wellness programs through the following actions:

1. Encouraging clients to take action to improve their health and fitness.

2. Providing a referral to an appropriate wellness program.

3. Measuring progress through health and fitness assessments.

The Quick Fit Program (QFP) also overcomes significant challenges faced by small businesses implementing a wellness program. These barriers are a lack of dedicated resources, lower profit margins, and limited access to commercial worksite vendors.

Here is how the program overcomes each of the three barriers:

1. A lack of dedicated resources - Small businesses don't have the resources to have a properly trained employee on staff to drive a wellness initiative. This barrier is overcome because San Luis Sports Therapy and our Quick Fit Program (QFP) will be a dedicated resource for small business clients. The turn-key Quick Fit Program (QFP) provides all the skilled professionals and other resources necessary at an affordable cost.

2. Lower profit margins - Small businesses tend to have lower profit margins on the products or services they sell. This leaves them with little money to spend on implementing their own wellness program. With the resources available to San Luis Sports Therapy, the Quick Fit Program (QFP) is able to serve as a practical, cost-effective gateway to wellness programs and provides access to a team of rehabilitation and fitness experts.

3. Limited access to commercial worksite vendors - Most commercial worksite 
vendors offer wellness products and services that are expensive, and require dedicated staff members within a company to implement. Most products and services offered are time intensive, expensive, and labor intensive. The Quick Fit Program (QFP) is designed to be accessible, low cost, and turn-key making it easy for small businesses.

\subsection{Market Analysis Summary}

The amount of reimbursement received for physical therapy services has remained largely flat over the past several years. In the same amount of time, the amount of required documentation has exponentially increased in volume as well as in complexity. The increase in documentation requirements with a relatively flat level of reimbursement does not keep pace with inflation. This effectively lowers the cost of reimbursement even further. These factors combine to produce lower levels of professional productivity due to extensive documentation time, and increased cost for additional office staff to support claims processing. The end result is working harder for less profit.

Physical therapy and rehabilitation have always been professions of healing, caring and educating. In the past 10 years, the industry has adapted and advanced their professional therapeutic skills to include a dual specialty of therapist and reimbursement coordinator manager. Physical therapists enter the profession of therapeutic rehabilitation to heal clients and provide education. The physical therapy and rehabilitation industry is now experiencing an everincreasing demand on time to complete extensive documentation required by multiple insurance companies.

The National APTA Medicare Fee Schedule Calculator provides average reimbursements for CPT codes from 2000 to present. For a physical therapy evaluation (97001) in upstate New 
York reimbursement rates have ranged from a low of $\$ 60.79$ in 2000 to a high of $\$ 73.19$ in 2005 and have continued to fall since that time. With reimbursement rates decreasing, physical therapy practices need to look for other sources of profit and reposition themselves in a changing healthcare environment.

Less revenue from reimbursements and a changing healthcare environment will likely drive many physical therapy practices out of business. To survive and prosper in this environment requires physical therapists to search for additional sources of revenue and to position themselves as a health and fitness resources in the community.

\subsection{Market Segmentation}

The Quick Fit Program (QFP) is intended as a gateway to wellness programs for small businesses. Participant San Luis Sports Therapy clinics will provide assessments, recommendations, and referral to internal or external resources as appropriate. Once the program

has been successfully implemented, there are several more market segments that could be users of the program.

Below are listed market segments that are potential users of the Quick Fit Program (QFP):

Small Businesses

Initially, this will be the primary market segment. In the current economic environment, small businesses are looking for ways to provide value to retain employees and reduce healthcare costs.

Discharged Physical Therapy Patients

When a person finishes their prescribed course of physical therapy, they are discharged. 
When a person is discharged they are simply finished and typically don't return to physical therapy unless required. The discharged patient will be most influenced by the recommendation of their physical therapist. They will be key in spreading the word about the program to family, friends, and other community members.

\section{Adult Members of the Local Community}

The majority of adults in California are health conscious and tend to make lifestyle choices that are preventative in nature. The Quick Fit Program (QFP) will appeal to this group as it will raise awareness about health and fitness, and may prevent the development of future injury or illness.

\section{Local Athletic Teams}

Local athletic teams may not have access to physical therapists unless they are injured and referred by their physician. Team services are also typically limited by the organizations budget, which does not always allow for the team to keep a physical therapist on staff. Therefore, the Quick Fit Program (QFP) offers a solution to a potential need of the local teams.

Personal Training Clientele

Clients of local gyms are a great source of potential clients as most gyms look for ways to develop a referral network in the community. Specifically, the sales staff and personal trainers at the local gyms would benefit the most from a relationship with a physical therapy clinic.

\subsection{Service Business Analysis}

Several fitness facilities and physical therapy practices are currently in operation on the Central Coast of California, none of which offer health and fitness assessments by physical therapists as part of a turn-key program for small businesses. Neither the fitness facilities nor 
physical therapy practices in the area offer the type of service provided by the Quick Fit Program (QFP). The program utilizes physical therapists and positions them in a role traditionally occupied by personal trainers and other allied health professionals. However, providing health and fitness assessments with recommendations are a natural extension of physical therapy. Physical therapists will be able to substantially increase the value of the assessments by utilizing their education, expertise, and skill.

\subsection{Strategy and Implementation Summary}

\subsection{S.W.O.T. Analysis}

Advantages and challenges are present considering the organizational structure of San Luis Sports Therapy. With centralized administrative and billing teams, we are able to streamline processes and cut costs per location by servicing multiple locations. This fact, in addition to the size of our company, allows for more specialization than competitors which positions us better than most for the upcoming challenges during these turbulent economic times.

\subsubsection{Strengths}

- A great team of highly skilled, motivated, and educated employees with the common goal of growing and bettering the company.

- Ability to streamline processes and cut costs per location by servicing multiple locations.

- The size of the San Luis Sports Therapy team allows for more specialization than competitors, which positions us better than most for the upcoming changes in a turbulent economy.

\subsubsection{Weaknesses}


- Lack of united direction in our clinics.

- Lack of ability to change and adjust.

- Lack of participation and collaboration.

\subsubsection{Opportunities}

- Resources to take advantage of growth opportunities presented by changes in healthcare.

- Ability to acquire new locations.

- Greater diversification of services.

\subsubsection{Threats}

- Medicare and Blue Cross changes have the potential to decrease allotted number of physical therapy visits and ultimately $15-20 \%$ of our revenue if we keep our business model the same and do not create new sources of revenue.

- Prescription and over-the-counter medications may be a quick and easy alternative to participating in the Quick Fit Program (QFP) to improve health or treat the symptoms of various conditions.

- Surgery may be an alternative to the Quick Fit Program (QFP) as people may prefer the "quick fix" over exercise.

\subsection{Implementation}

The assessments performed in Quick Fit Program (QFP) must be tailored to 30 minutes. This time constraint was created to a time frame acceptable to participating physical therapists. 
The goal is for the client to spend the first 15 minutes with a physical therapy aide and the remaining 15 minutes with a physical therapist. This further breaks up the sessions into a realistic time frame that a physical therapist would accept. Taking too much of a physical therapists time for the assessments would be counterproductive for both the physical therapist and client.

Due to the established time constraints, systems and procedures will be created to facilitate a valuable session for the client and a cost-effective program for physical therapy clinic directors.

San Luis Sports Therapy has a very large potential market. Because of the uniqueness of the Quick Fit Program (QFP), there is potential to become the leader in wellness programming. This will be accomplished by actively and continuously promoting the program through our physical therapy clinics throughout California as well as by hosting and supporting various community events to establish the Quick Fit brand.

\subsection{Competitive Edge}

Despite the enormous potential for wellness programs to improve the health of employees in the United States, most small businesses fail to adopt a wellness program while encountering the following three significant challenges:

1. Lack of dedicated resources

2. Lower profit margins

3. Limited access to commercial worksite vendors

The Quick Fit Program (QFP) meets the needs of small businesses by providing a wellness program solution by addressing the three significant challenges listed above. The size 
and rate of growth of San Luis Sports Therapy allows us to use economies of scale to implement the Quick Fit Program (QFP) is the most efficient, cost-effective manner possible. This is an advantage that most physical therapy practices do not possess.

\subsection{Marketing Strategy}

The marketing strategy is the core of the main strategy:

1. Promote the Quick Fit Program (QFP) as a turn-key, effective, cost saving wellness program for small businesses.

2. Market the Quick Fit Program (QFP) as a value added service to help small business retain and recruit healthy, happy, and productive employees.

3. Build on-going relationships with local businesses and members of the community.

\subsection{Sales Strategy}

The overall strategy is to sell the Quick Fit Program (QFP) to small businesses in the community. As the number of clients increase, marketing efforts by the end of year one could potentially expand to include other physical therapy practices looking to increase revenue by adding a new service. Through referrals by physical therapists and physicians, testimonials from clients, we will demonstrate value in the program.

\subsection{Management Summary}

The Quick Fit Program (QFP) is a turnkey program that will be managed by the director of the participating physical therapy clinic. The San Luis Sports Therapy team will provide operational support to participating clinics. Operational support will include the following: 
5. Design of marketing material is not limited to, but will include brochures, client handouts, posters, and web site design and maintenance.

6. Periodic questionnaires sent to clients to solicit feedback.

7. Tracking of program metrics.

8. Training/certification of staff.

\subsection{Personnel Plan}

All work in implementing the program at the clinics will be performed by existing staff at the physical therapy clinic. A physical therapy aide will perform the assessments during the first 15 minutes with the client. After the assessment, the client will meet with a physical therapist to review assessment results and answer any questions. The physical therapist will conclude by creating an action plan and schedule a follow up assessment. The action plan will consist of strategies and an exercise plan for the client to improve their score on the follow up assessment.

Assessments will be scheduled during normal business hours and will not require additional payroll expense.

\subsection{Financial Plan}

Below are estimated financials for the Quick Fit Program (QFP) implemented in all thirteen San Luis Sports Therapy clinics in California.

\begin{tabular}{lc|c|c|c|c} 
& Year 1 & Year 2 & \multicolumn{1}{c}{ Year 3 } & \multicolumn{1}{c}{ Year 4 } & Year 5 \\
\cline { 2 - 6 } Total Units Sold & 1,352 & 5,408 & 10,816 & 13,520 & 16,900 \\
\hline Unit Price & $\$ 9.99$ & $\$ 12.99$ & $\$ 15.00$ & $\$ 24.99$ & $\$ 29.99$ \\
\hline Unit Cost & $\$ 13.98$ & $\$ 13.98$ & $\$ 13.98$ & $\$ 13.98$ & $\$ 13.98$ \\
\hline
\end{tabular}




\begin{tabular}{ll|l|l|l|l} 
Total Revenue & $\$ 13,506$ & $\$ 70,250$ & $\$ 162,240$ & $\$ 337,865$ & $\$ 506,831$ \\
\hline Total Cost & $\$ 18,894$ & $\$ 75,577$ & $\$ 151,154$ & $\$ 188,942$ & $\$ 236,178$ \\
\hline Profit & $-\$ 5,388$ & $-\$ 5,327$ & $\$ 11,086$ & $\$ 148,923$ & $\$ 270,654$ \\
\hline
\end{tabular}

\section{Financial Assumptions}

- $\quad$ Total Units Sold - For Year 1 it was assumed two Quick Fit assessments per clinic per week were sold. Growth rates were then assumed to be $400 \%, 200 \%, 25 \%$, and $25 \%$ respectively.

- $\$ 32$ per hour average rate of pay for a physical therapist at San Luis Sports Therapy.

- $\$ 11$ per hour average rate of pay for a physical therapy aide at San Luis Sports Therapy

Unit cost was arrived at by adding together the average hourly wage for a physical therapist and physical aide at San Luis Sports Therapy, dividing by four since each would work 15 minutes, then adding $30 \%$ to account for benefits and payroll taxes. Other costs were considered fixed costs and were not factored in since they would be incurred whether or not Quick Fit assessments were sold.

Unit price was based on a 53.4\% profit margin by end of Year 5. Unit price in earlier years were chosen to gain market share. As market share increased, Unit Price was increased in Year 3 to recover losses from the first two years. 